\title{
The Contact Simulation Comparison of UHMWPE to the Crosslink Intensity Effect
}

\author{
Reza Azizul Nasa Al Hakim¹, Sigit Arrohman ${ }^{1}$, Eko Saputra ${ }^{1}$, Iwan Budi Anwar ${ }^{2}$, J Jamari ${ }^{1}$, Rifky Ismail ${ }^{1}$, Athanasius P. \\ Bayuseno $^{1}$, and Mohammad Tauviqirrahman ${ }^{1}$ \\ ${ }^{1}$ Department of Mechanical Engineering, Faculty of Engineering, Diponegoro University, Semarang - Indonesia \\ ${ }^{2}$ Prof DR. R. Soeharso Orthopaedic Hospital, Solo - Indonesia
}

\begin{abstract}
Ultra High Molecular Weight Polyethylene called UHMWPE is a unique polymer material that has excellent physical and mechanical properties. UHMWPE material is frequently used in prosthesis. One example of UHMWPE uses in prosthesis is acetabular liner which is one component for Total Hip Joint Replacement (THR) and can also be found for bearing surfaces on the knee, ankle, shoulder, and connective tissue of the joint. UHMWPE material is made by compression molding process. However, UHMWPE wear often causes the failure of artificial hip joints. Therefore, a treatment to reduce the crosslink method is performed. The purpose of this study was to determine the crosslink effect in UHMWPE material. The method used for this analysis is ABAQUS 6-13 software. On bipolar model, the $3000 \mathrm{~N}$ load is applied in the FEM model. The crosslink dose used in this analysis was $50 \mathrm{kgy}, 75 \mathrm{kgy}$, and $100 \mathrm{kgy}$. The results obtained are that UHMWPE that has received by gamma irradiation treatment can receive a smaller stress distribution. The results of the simulation for UHMWPE without irradiation produced 0.759 stress distributions; 50kgy crosslink dose has 0.666 stress distributions; 75kgy crosslink dose has 0.662 stress distributions; and 100kgy crosslink dose has 0.660 stress distributions. This result proved that UHMWPE which has received crosslink can receive a better stress distribution. For the result crosslink with 100kgy dose received the best number of stress distributionss.
\end{abstract}

Keywords: UHMWPE; Compression Molding; Crosslink; Total Hip Joint Replacement.

\section{Introduction}

Polymers are derived from the Greek which consist of two words, poly means large and merous means the part or unit. So, polymer is defined as a large molecule (macro molecule) formed of the reorganization of small and simple chemical units [1]. The polymer classification based on the thermal properties is divided into 2 classes, thermo-set and thermoplastic polymers [2].

Ultra high molecular weight polyethylene (UHMWPE) is a unique polymer material known for excellent physical and mechanical properties. In orthopedic prosthesis, this material is used for implant replacement parts of damaged human body [3]. UHMWPE has been commonly used for hip joint replacement because of its excellent properties such as good bio-compatibility. However, the wear and dust of UHMWPE often leads to leeway and failure in artificial hip joints. Many techniques have been applied in modifying polymer to improve UHMWPE surface [4]. There were some researches been conducted to test the reliability of artificial hip joint on several activities like salat movement [5]-[7] and other light daily activities [8]. There are 4 methods in the UHMWPE manufacture process, compression molding, extrusion molding, hot isostatic pressing of armCom and direct compression molding. Compression molding is a process in which UHMWPE powder is put into the mold and heated until melted, and then mold will press the melted UHMWPE powder to get the solid UHMWPE shape [9]. Fig. 1 is the example of UHMWPE material.

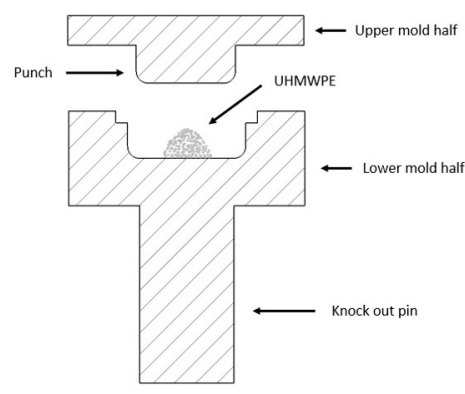

(1)

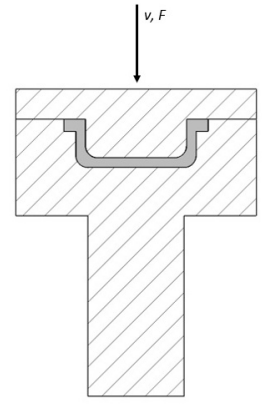

Fig. 1. Compression molding process

In order to overcome the previous problems regarding to UHMWPE, the surface strength should be increased to reduce wear and tear [10]-[11]. Acetabular liner geometric design for total hip joint replacement (THR), using UHMWPE (either polymer on metal),

Corresponding author: rezazizul@gmail.com 
allows the construction of the total hip joint replacement to be lighter compared to the local metal on the construction of metal hip joint replacement. This combination has been tested to have wear resistance that is comparable to the combination of metal on metal material. Fig. 2 is the example of acetabular component.

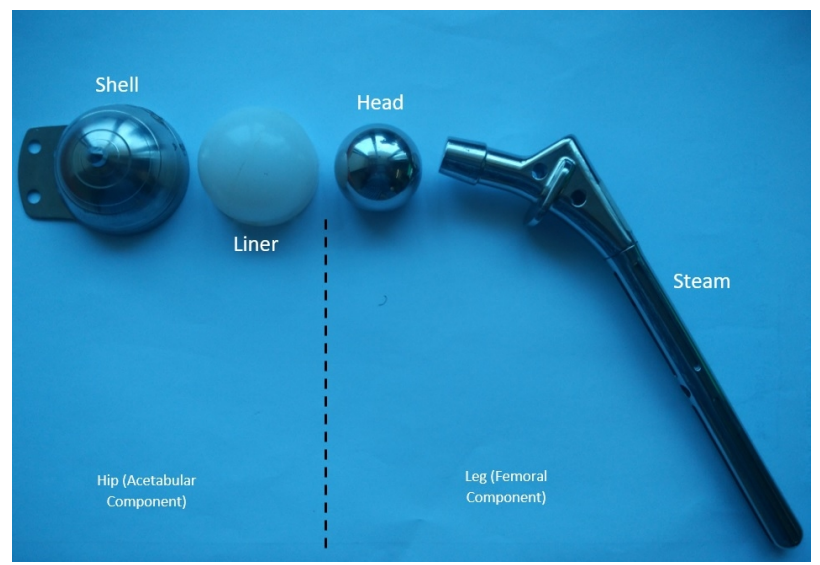

Fig. 2. Acetabular component

Gamma rays is a high electromagnetic energy waves in the form of energy packages (photons) [12]. Gamma rays are generally sourced from cobalt-60 isotope $(60 \mathrm{Co})$ and have a shorter wave length than UV light, which is $0.01-10-6 \mathrm{~nm}$ [13]. The interaction between gamma radiation and the material or energy absorption by the material causes the photoelectric effect, compton scattering, and pair production. These three processes can produce electrons that can excite molecules. The ions formed will quickly interact with electrons and cause molecular excitation. Excited molecules will split into free radicals. Free radical species produced from gamma ray on polymers play an important role in subsequent reactions in which polymer can experience chain breakage and form crosslinks. Fig 3 is the process of breaking $\mathrm{C}-\mathrm{H}$ bond.

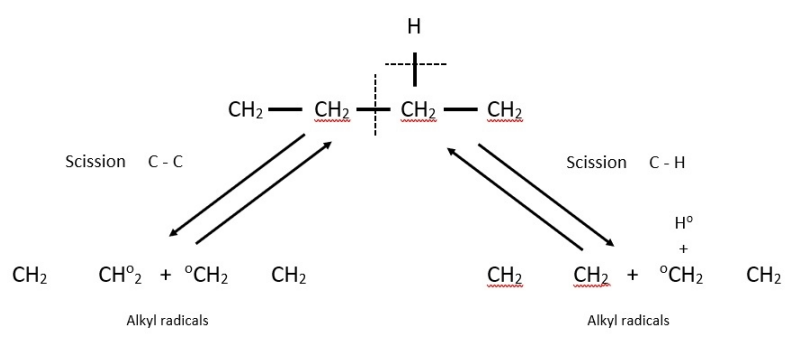

Fig. 3. The process of breaking the $\mathrm{C}-\mathrm{H}$ bond in one polymer chain

Cross-linking is formed of a process of breaking the $\mathrm{C}-\mathrm{H}$ bond in a polymer chain in the amorphous phase to form free-moving free radicals to bind to free radicals found in other polymer chains, but in an oxygen- free state [14]. Crosslinking in polymers can produce a threedimensional structure so that it will increase the mechanical strength, melting point, and molecular weight as the dose of irradiation increases [12]. Chain break is a process of breaking C-C bonds in the presence of oxygen so that the oxygen binds or captures the free radicals produced [14].The main focus of this paper was to calculate the stress distribution that occurred in the acetabular by irradiation treatment with different crosslink intensity.

\section{Material and Methods}

\subsection{Material modelling}

FEM that presented uses UHMWPE material with different crosslink intensities. The crosslink intensity used in this model is $50 \mathrm{kgy}, 75 \mathrm{kgy}$, and $100 \mathrm{kgy}$. The simulation consists of 4 components: head, liner, outer liner, and cup. This simulation uses 2D modeling and the $3000 \mathrm{~N}$ load is applied in the center point of head. The mechanical properties from each crosslinked of UHMWPE can be seen in Table 1 .

Table 1. Mechanical properties of UHMWPE

\begin{tabular}{|c|c|c|c|}
\hline UHMWPE & $\begin{array}{c}\text { UTS } \\
(\mathbf{M P a})\end{array}$ & $\begin{array}{c}\text { Yield Strength } \\
(\mathbf{M P a} \boldsymbol{)}\end{array}$ & Ref. \\
\hline $50 \mathrm{kgy}$ & 37 & 19.6 & Ref. [15] \\
\hline $75 \mathrm{kgy}$ & 37 & 19.9 & Ref. [15] \\
\hline $100 \mathrm{kgy}$ & 35 & 20.2 & Ref. [15] \\
\hline
\end{tabular}

The Finite Element Method (FEM) is used to calculate the force occurred with UHMWPE with 50, 75, and 100kgy intensity. In FEM simulation, the material that changes is only the liner while the other material is fixed and ignored [15].

\subsection{FEM (Finite Element Method)}

\subsubsection{Geometry}

The geometrical modeling of the bipolar in this study used the current model of prototype which was developed in Diponegoro University. For the FEM size models can be seen in Table 2. Fig. 4 shows geometrical model for the current study. The type of element used was 4 nodes bilinear axisymmetric quadrilateral. The mesh which is used in the study is 42186 elements.

Table 2. Geometri size of bipolar

\begin{tabular}{|c|c|c|c|c|}
\hline \multirow{2}{*}{ Diameter (mm) } & \multicolumn{4}{|c|}{ Bipolar model } \\
\cline { 2 - 5 } & Head & Liner & Outer & Cup \\
\hline Inner diameter & - & 28.2 & 40.2 & 45.2 \\
\hline Outer diameter & 28 & 40.2 & 45 & 50 \\
\hline
\end{tabular}




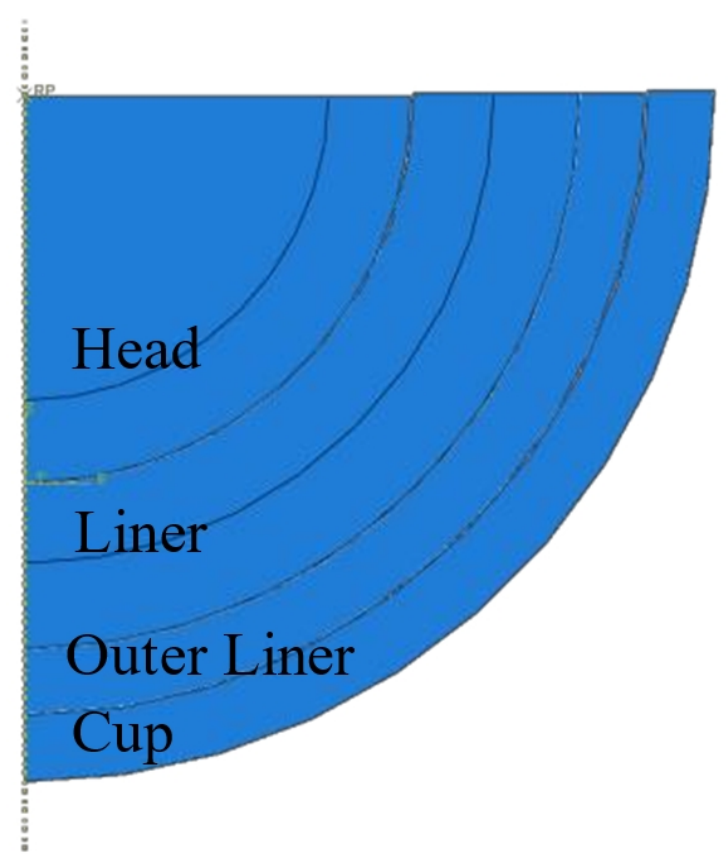

Fig. 4. The geometrical modeling of bipolar models

\subsubsection{Boundary Condition}

The given force is $3000 \mathrm{~N}$ in the direction of the $\mathrm{Y}$ axis and applied to the model center point. The outer cup surface is fixed for all direction. Fig. 5 shows the direction of the applied load and fixed direction for the model.

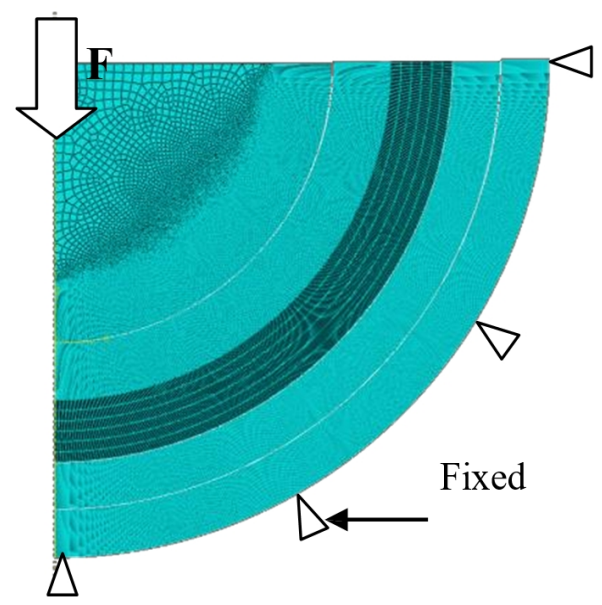

Fig. 5. Applied forces on the bipolar model assembly.

\section{Results and Discussion}

\subsection{Validation}

The comparison of the maximum contact result between the theory and the simulation is used as the validation. Fig. 4 shows the maximum stress on the model compared to Hertz and Bartel theory [16]. In the modeling, the maximum stress result occurred in the of the liner. Based on this comparison, it can be seen that the maximum stress that occurs in the modeling and in Bartel theory, with the same $3000 \mathrm{~N}$ load, has about $5.7 \%$ differences. In the picture there is a little bit difference between Bartel theory and Present theory, so in this case Bartel theory is more recommended. Fig. 6 shows the countur plot of contact stress on liner surface.

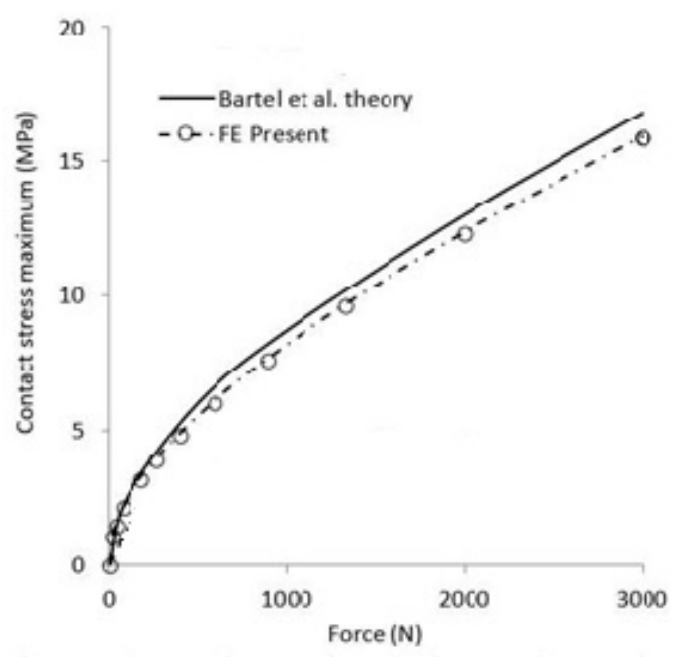

Fig. 6. The comparison of contact stress on the liner for Bartel theory and Present model

\subsection{Contact Stress Distribution}

Fig. 7, Figure 8, Fig. 9, and Fig. 10 show the stress distribution over the present liner with a load of $3000 \mathrm{~N}$. Fig. 7 shows the result FEM from UHMWPE stress distribution with $0 \mathrm{kgy}$ irradiation. Fig. 8 shows the result FEM from UHMWPE stress distribution with 50kgy irradiation. Fig. 9 shows the result FEM from UHMWPE stress distribution with $75 \mathrm{kgy}$ irradiation. Fig. 10 shows the result FEM from UHMWPE stress distribution with $100 \mathrm{kgy}$ irradiation.
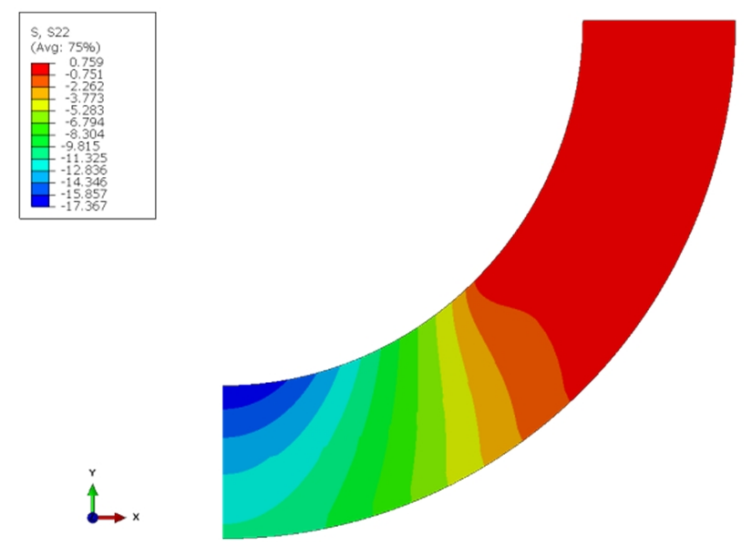

Fig. 7. Stress distribution over the present liner with $0 \mathrm{kgy}$ irradiation. 


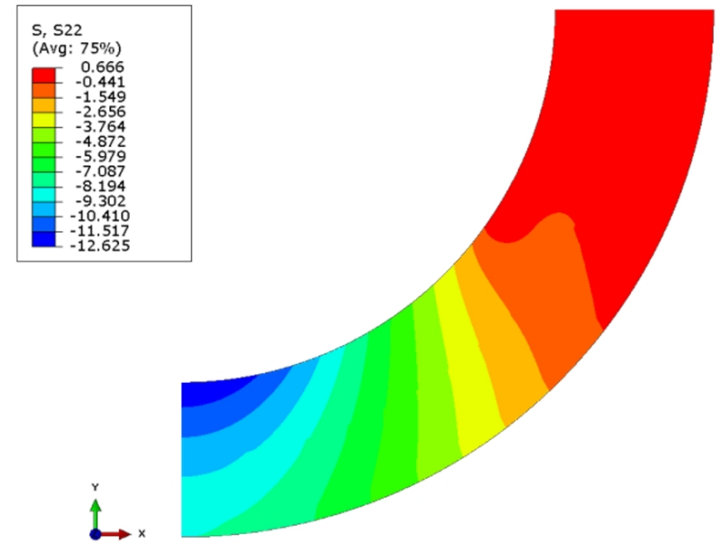

Fig. 8. Stress distribution over the present liner with 50kgy irradiation.

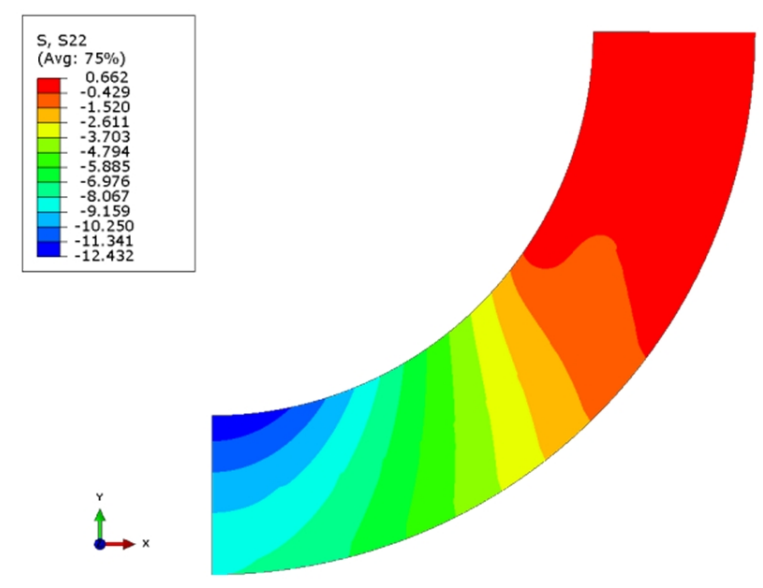

Fig. 9. Stress distribution over the present liner with $75 \mathrm{kgy}$ irradiation.

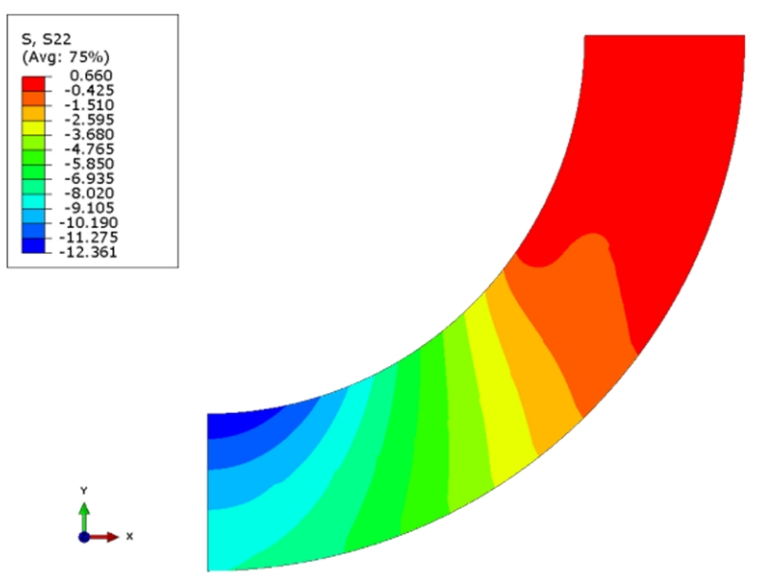

Fig. 10. Stress distribution over the present liner with $100 \mathrm{kgy}$ irradiation.

Fig. 11 shows the stress distribution that works on the present liner. From Fig 7-10 stress distribution for 0kgy irradiation is $0.759,50 \mathrm{kgy}$ irradiation is $0.666,75 \mathrm{kgy}$ irradiation is 0.662 , and $100 \mathrm{kgy}$ irradiation is 0.660 .

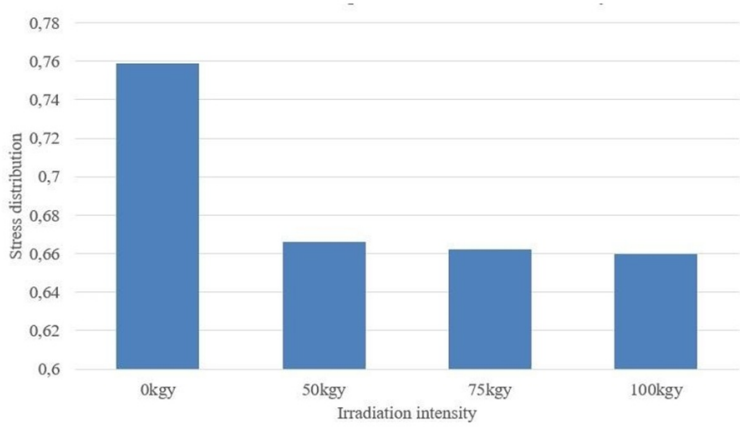

Fig. 11. Contact simulation comparison of crosslink intensity.

\section{Conclusion}

This paper investigated the stress distribution that occurred on liner with $3000 \mathrm{~N}$ load. From these result it can be concluded that UHMWPE that has been through the crosslink process has better stress distribution compared with UHMWPE that is not in the crosslink. The greatest stress distribution occurs on the $100 \mathrm{kgy}$ crosslink irradiation. This study is interpretation of the development of low carbon society.

\section{References}

1. R. O. Ebewele, Polymer science and technology, (CRC press, 2000)

2. F.W. J. Billmeyer, Textbook of polymer science, (Wiley Interscience, New York, 1984)

3. S. M. Kurtz., UHMWPE biomaterials handbook: ultra high molecular weight polyethylene in total joint replacement and medical devices, (Academic press, 2009)

4. A. Oztarhan, ES. Urkac, N. Kaya, M. Yenigul, F. Tihminlioglu, A. Ezdasir, R. Zimmerman, S. Budak, C. Muntele, B. Chhay, D. Ila, Modification of surface morphology of UHMWPE for biomedical implants, (MRS Online Proceedings Library Archive, 2007)

5. J. Jamari, R. Ismail, E. Saputra, S. Sugiyanto, and I. B. Anwar, The Effect of Repeated Impingement on UHMWPE Material in Artificial Hip Joint during Salat Activities, Adv. Mater. Res., 896, 272-275 (2014)

6. R. Ismail, E. Saputra, and M. Tauviqirrahman, Numerical Study of Salat Movements for Total Hip Replacement Patient, Appl. Mech., 493, 426-431, (2014)

7. E. Saputra, I. B. Anwar, J. Jamari, and E. van der Heide, A Bipolar Artificial Hip Joint Design for Contact Impingement Reduction, Adv. Mater. Res., 1123, 164$168,(2015)$

8. E. Saputra, I. B. Anwar, J. Jamari, and E. Van Der Heide, Finite element analysis of artificial hip joint movement during human activities, Procedia Eng., 68, 102-108, (2013)

9. S. M. Kurtz, O. K. Muratoglu, M. Evans, and A. A. Edidin Advances in the processing, sterilization, and crosslinking of ultra-high molecular weight polyethylene for total joint arthroplasty, Biomaterials (20), 18, 1659-1688, (1999) 
10. H. A. McKellop, F. W. Shen, B. Lu, P. Campbell, R. Salovey, Effect of sterilization method and other modifications on the wear resistance of acetabular cups made of ultra-high molecular weight polyethylene: a hipsimulator study, JBJS (82), 12, 1708-1725, (2000)

12. V.S. Ivanov. Radiation chemistry of polimers. 5. Vsp, (1992)

13. V. Harten, A. Marcus. Mutation breeding : theory and practical applications. Cambridge University Press, (1998)

14. Blunn, Gordon, EM Brach Del Preva, Luigi Costa, J. Fisher, and M. A. R. Freeman. Ultra high molecular- weight polyethylene (UHMWPE) in total knee replacement: fabrication, sterilisation and wear. The Journal of bone and joint surgery, British volume (7), 84, 946-949, (2002)

15. O.K. Muratoglu, C. R. Bragdon, D. O. O'Connor, M. Jasty, W. H. Harris, R. Gull, F. McGarry, Unified wear model for higly crosslinked ultra-high molecular weight polyethylene UHMWPE, Biomaterials (20), 16, 14631470, (1999)

16. E. Saputra, I. B. Anwar, R. Ismail, J. Jamari, and E. Van Der Heide, Study of unipolar and bipolar hip prostheses using finite element simulation: contact stress analysis, In Key Engineering Materials, 739, 96-102, (2017) 